\title{
Ziraat Fakültesi Öğrencilerinin GDO’lara Bakış Açısı: Çanakkale Onsekiz Mart Üniversitesi Örneği
}

\author{
*iskender TIRYAKi \\ Eda VATAN
}
Çanakkale Onsekiz Mart Üniversitesi, Ziraat Fak., Tarımsal Biyoteknoloji Bölümü, Çanakkale
*Sorumlu yazar e-posta (Corresponding author; e-mail): itiryaki@comu.edu.tr

Öz

Bu çalışma, kamuoyunu zaman zaman çok yoğun bir şekilde meşgul eden Genetiği Değiştirilmiş Organizmalar (GDO) ile ilgili olarak Çanakkale Onsekiz Mart Üniversitesi, Ziraat Fakültesi öğrencilerinin bilgi seviyelerini tespit etmek ve yaklaşımlarını belirlemek amacıyla yürütülmüştür. Çalışmada öğrencilere Genetiği Değiştirilmiş Organizmalar (GDO), Genetiği Değiştirilmiş Bitkiler (GDB), Transgenik Bitkiler ile bunların etkileri konularında farklı sorular yöneltilmiştir. Ana kitle oranlarına dayalı kümelendirilmiş tek aşamalı tesadüfi olasılık örnekleme yöntemi ile belirlenmiş toplam 384 öğrenci ile yapılan anket çalışmasında öğrencilerin konu ile ilgili sorulara verdikleri yanıtlar "evet", "hayır" ve "fikrim yok" olarak değerlendirilmiş ve veriler tanımlayıcı istatistik ile SPSS programı kullanılarak analiz edilmiştir. Öğrencilerin sorulara verdikleri yanıtlar bir yorum skalası geliştirilerek analiz edilmiştir. Çalışma sonuçları, yüksek eğitim seviyesine sahip, yeni teknolojiler ile bu teknolojilerin ürünlerini kabullenme ve kullanma konusunda çok istekli olan üniversite öğrencilerinin GDO konusundaki yaklaşımlarının belirsiz ve konu ile ilgili bilgi birikimlerinin ise yetersiz olduğunu göstermiştir.

Anahtar Kelimeler: GDO, transgenik bitki, üniversite

\section{GMOs Perspectives of Faculty of Agriculture Students: Example of Canakkale Onsekiz Mart University}

\begin{abstract}
This study was conducted to determine knowledge levels of faculty of agriculture students and their approaches about GMOs which keep very busy to public from time to time. Students were asked different questions about Genetically Modified Organisms (GMOs), Genetically Modified Plants (GMPs), Transgenic Plants and their effects. A total of 384 students determined by randomized single level possibility sampling method with main mass portion were used on the survey. Answers of students were evaluated as 'yes', 'no' and 'no idea' and results were analyzed by descriptive statistics using SPSS program. Answers of students were analyzed based on a scale developed by students' commentary. Results revealed that approaches of university students about GMOs are not well determined and their knowledge is not sufficient even though they have a high level of education and are willing to accept and use other new technologies.
\end{abstract}

Keywords: GMOs, transgenic plant, university

\section{Giriş}

G ıda eksikliğinin giderilmesi insanlığın başlangıcından bu yana yerleşik hayata geçişlerin, savaşların ve göçlerin en büyük nedenlerinden birini oluşturmuştur. Artan dünya nüfusu ve azalan tarım alanları, geçmişten günümüze devam eden bir süreç dahilinde birim alandan daha fazla ürün alınmasını zorunlu hale getirmiştir. Yüksek verim veren yeni bitki çeşitlerinin geliştirilmesi yanında var olan bitkilerin biyotik ve abiyotik stres etmenlerine karşı tolerant/dayanıklı hale getirilmesi, mekanizasyona uygunluğu, kalite kriterlerinin intiyaca yönelik olarak değiştirilmesi yukarıda belirtilen hedeflere ulaşmak amacıyla yapılan tarımsal uygulamalar olmuştur. Ancak, günümüzde bu amaçla yapılan introdüksiyon, melezleme, poliploidive mutasyon gibi klasik ıslah yöntemleri ve bu yöntemler kullanılarak elde edilen bitkisel ürünler tüketicinin dikkat ve tepkisini çekmez iken günümüzde aynı temel amaçlarla yapılmaya çalışılan modern biyoteknolojik uygulamalar ve bu uygulamaların ürünleri olan transgenik bitkiler hep tartışma konusu olmuştur. Söz konusu tartışmaların temelinde klasik ve modern biyoteknolojik yöntemlerin neler olduğu, klasik yöntemlere 
olan benzerlik ya da farklııkları ile amacının neler olduğu konusunda temel bilgi eksikliğinin var olduğu görülmektedir. Bitki ıslahı amacıyla yapılan modern biyoteknolojik uygulamaların en önemli çıktılarından biri olan genetiği değiştirilmiş bitkiler ya da daha genel bir ifade ile Genetiği Değiştirilmiş Organizmlar (GDO) hakkında basın ve yayın kuruluşları ile sosyal medyada, genelde konu uzmanı olmayan medyatik kişiler tarafından tek yönlü olarak yapılan bilgi aktarımı bu konunun gerçek anlamda ele alınmasını güçleştirmektedir. Yanlış edinilen fikirlerin doğru bilgilerle değiştirilmesi ya da güncellenmesi ise oldukça güç gözükmektedir.

Bugünkü biyoteknolojik yöntemlerle genetik bilimi kullanılarak elde edilmiş bitkiler, genetiği değiştirilmiş bitkiler (Genetically Modified Crops. GD-Plants), transgenik bitkiler, genetik mühendisliği aracılığı ile elde edilmiş kabul gören ve en hızlı yayılan tarımsal teknoloji olarak karşımızda durmaktadır (Şekil 1; Çizelge 1).

Modern biyoteknolojinin tarıma uygulanmasının bir sonucu olarak ortaya çıkan genetik mühendisliği genel olarak; 'organizmalar arasındaki genetik alışveriş işlemine aracı olma veya müdahale etme' şeklinde tanımlanmaktadır. Daha açık bir ifadeyle genetik mühendisliği 'herhangi bir organizmanın (bitki, hayvan ya da mikroorganizma) genetik yapısının moleküler teknikler kullanılarak değiştirilmesi' şeklinde tanımlanmaktadır (Duvick 2001). Burada farkındalık, genetik değişikliğin bizzat kendisi olmayıp elde edilen genetik değişikliğin ya da modifikasyonun hangi yöntemler kullanılarak elde edildiği bilgisidir. Bu nedenle son zamanlarda genetik modifikasyonlarda kullanılan genin kaynağı ayrı bir tartışma konusu oluşturmaktadır. Bu kapsamda yakın ve

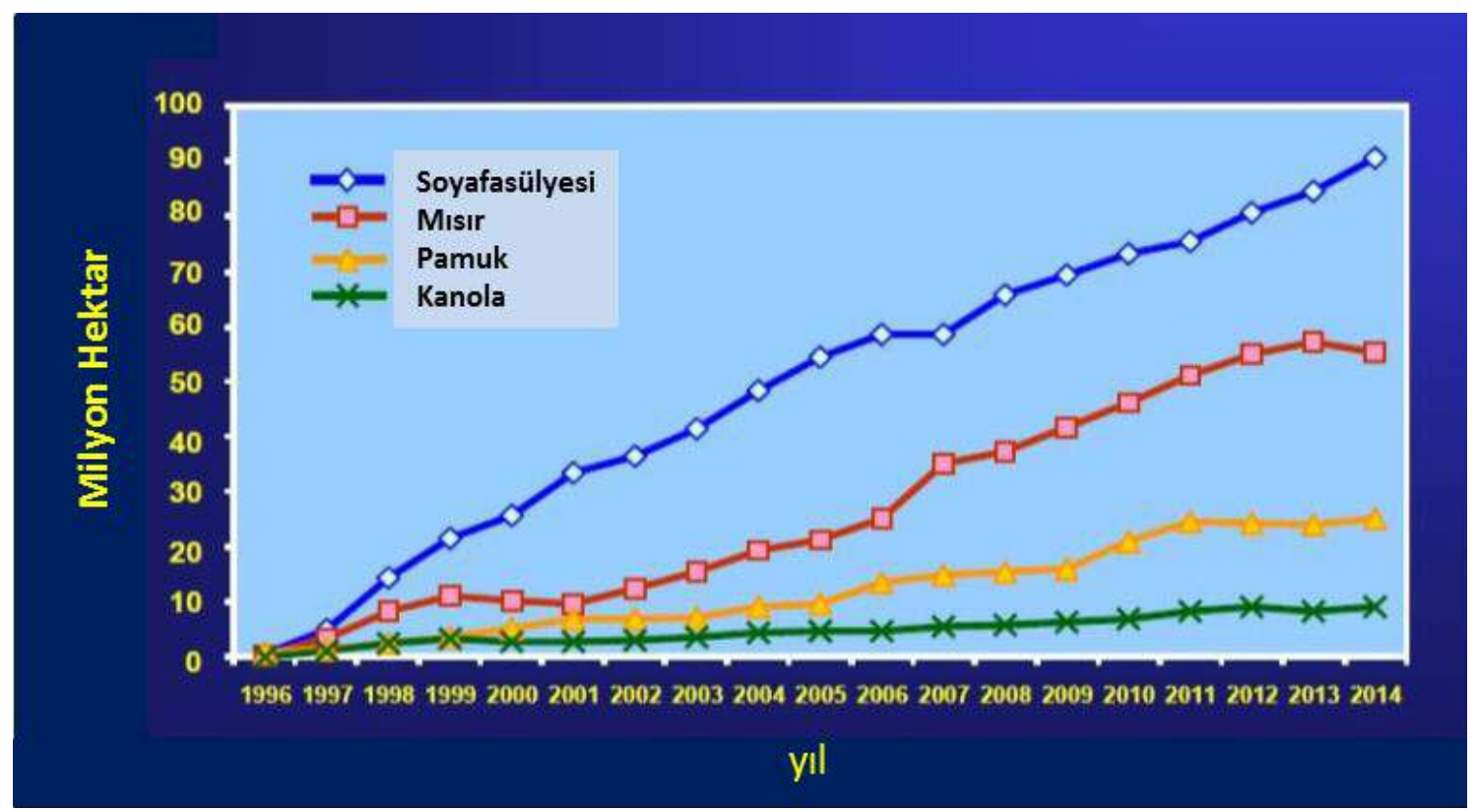

Şekil 1. Dünya da 1996-2014 yılları arasında GD bitkilerin ekim alanları (James 2014)

Figure 1. GMO cultivation areas in the World between 1996-2014 based on plant species (James 2014)

bitkiler (GeneticallyEngineeredCrops), genetiği değiştirilmiş yaşayan organizmalar (Genetically Modified Living Organisms) veya daha da genel anlamıla tüm canlıları (organizmları) kapsayan genetiği değiştirilmiş organizmalar (Genetically Modified Organisms) ifadesi yaygın olarak kullanılmaktadır. Genelde Avrupa kökenli oluşturulan karşıt görüş ve tartışmalara rağmen dünya genelinde 28 ülkede 181.5 milyon ha alanda ekimi (James, 2014) yapılan transgenik bitkiler, adaptasyon ve uygulama açısından değerlendirildiğinde dünya genelinde en çok uzak gen transferleri ile var olan genin modifikasyonuna yönelik biyoteknolojik uygulamalar GDO konusundaki tartışmaları daha da karmaşık hale getirmektedir.

Bu çalışma ekonomik, sosyal ve kültürel boyutları yanında bilimsel yönleri ile oldukça kapsamlı ele alınması gereken GDO konusunda, toplumun en eğitimli kesimini oluşturan üniversite öğrencilerinin ve özellikle de tarımsal uygulamalar ve kullanılan yöntemler konusunda çok farklı dersler alma şansı bulan Ziraat Fakültesi öğrencilerinin GDO ile ilgili bilgi 
seviyelerini tespit etmek ve GDO'ya bakış açılarını belirlemek amacıyla yapıımıştır.

\section{Materyal ve Yöntem}

Araştırmada Çanakkale Onsekiz Mart Üniversitesi, Ziraat Fakültesinin farklı bölüm ve sınıflarında öğrenim gören öğrencilerle, yüz yüze görüşmek kaydı ile 384 anketten elde edilen veriler kullanılmıştır. Tarımsal Biyoteknoloji Bölümü öğrencilerinin konuyla ilgi olarak farklı duyumlarının var olduğu ve değişik derslerde konuyla ilgili tartışmalara katılmaları nedeni ile diğer bölüm öğrencileri ile mukayese edilmemeleri gerektiği düşünüldüğü için bu öğrenciler anket çalışmasına dahil edilmemiştir. Diğer bölüm öğrencilerinin GDO hakkında ne kadar bilgi sahibi oldukları bilinmediği için araştırmanın örnek hacmi, ana kütle oranlarına dayalı kümelendirilmiş tek aşamalı tesadüfi olasılık örnekleme yöntemi ile belirlenmiştir (Collins, 1986).

$n=t^{2} \cdot[1+(0.02) \cdot(b-1)] \cdot(p \cdot q) / e^{2}$

$\mathrm{n}$ : örnek hacmi

t: \%95 önem derecesine karşlık gelen tablo değeri

b: örnekleme aşaması (bu aşama tek aşamalı olduğu için 1 alınmıştır)

$\mathrm{p}$ : incelenen olayın gerçekleşmeme olasılığı $\% 50$ olarak alınmıştır.

q: incelenen olayın gerçekleşmeme olasılığı (1-p)

e: kabul edilen hata payını (bu çalışmada $\% 5$ olarak alınmıştır) ifade etmektedir.

$\mathrm{b}=1$ alındığında denklem; $\mathrm{n}=\mathrm{t}^{2}$. ( $\left.p . q\right) /$ e bu şekli almaktadır, değerler yerine koyulduğunda; $\mathrm{n}=(1.96)^{2} .(0.5 .0 .5) /(0.05)^{2} \mathrm{n}=384$ olarak bulunmuştur.

Çalışmada, öğrencilerle yüz yüze görüşülerek kişilerin sosyo-ekonomik durumları dikkate alınmadan 17 sorudan oluşan toplam 384 anket uygulanmıştır. Sorulara verilen cevaplar 'Evet', 'Hayır' ve 'Fikrim Yok' olarak belirlenmiştir. Belirlenen amaçlar doğrultusunda elde edilen veriler tanımlayıcı istatistik yardımıyla SPSS (16.0) paket programı kullanılarak analiz edilmiştir.

\section{Bulgular ve Tartışma}

Çalışmada kullanılan anket soruları ve öğrencilerin bu sorulara verdikleri cevaplar ve dağılım durumları Çizelge 2'de sunulmuştur. Ankete katılan 384 öğrencinin bölümlere göre dağılımlarına bakıldığında \%15.4 "Bahçe
Bitkileri", \%29.2 "Bitki Koruma", \%18.0 "Tarım Ekonomisi", \%1.6 "Tarım Makinaları ve Teknolojileri Mühendisliği", \%4.7 "Tarımsal Yapılar ve Sulama", \%16.2 "Tarla Bitkileri”, \%0.5 "Toprak Bilimi ve Bitki Besleme" ve \%14.4 "Zootekni" bölümlerinden oldukları belirlenmiştir. Bazı bölümlere ait öğrenci sayılarının az olması bu bölümlere yeni öğrenci kayıtlarının olmamasından kaynaklanmaktadır.

Analiz sonuçlarına göre ankete katılan 384 öğrencinin yaş ortalaması 21 olarak tespit edilmiştir. Ankete katılan öğrencilerin \%39.6'sı "Bayan" \%60.4' ü "Bay" olarak belirlenmiştir.Ankete katılan öğrencilerin \% 28.6'। 1. sınıf, $\% 27.7$ ' 2. sınıf, $\% 23.5$ 'ü 3. sınıf ve \%20.2'nın 4. sınıf öğrencisi olduğu tespit edilmiştir. Ankete katılan öğrencilerin 'GDO'ların insan sağlığı ve çevre açısında zararlı olduğunu düşünüyor musunuz?' sorusuna \%85.9 oranında 'Evet' cevabı verdikleri, 'GD bitki ya da gıdaların üzerinde GDO'lu olduğunun belirtilmesi durumunda satın alır mısınız?' sorusuna ise \%72.1 oranında 'Hayır' cevabı verdikleri tespit edilmiştir. 'Sizce günümüzde kanser ve şeker hastalıklarının bu kadar yaygınlaşmasında GDO'ların doğrudan bir katkısı var mıdır?' sorusuna 'evet' diyenlerin oranı \%63.5 olurken, 'GD bitki ya da gıdalar güvenli midir?' sorusuna \%72.0 oranında 'Hayır' olarak cevaplamışlardır. 'GD bitki ya da gıdaların üzerinde GDO'lu olduğunun belirtilmesi durumunda satın alır mısınız?' sorusuna \%72.1 oranında 'hayır' cevabı verilmiştir. 'GDO kullanımının sigara ya da cep telefonu kullanımına göre insan sağlığına daha zararlı olduğunu düşünüyor musunuz?' sorusuna 'evet' diyenlerin oranı \%41.3 olurken, 'GD bitki ve gıdaların, yanlış zaman ve ölçüde kullanılan tarım ilaçlarından daha tehlikeli olduğunu düşünüyor musunuz?' sorusuna 'evet diyenlerin oranı \%45.9 olarak tespit edilmiştir. 'Modern Biyoteknolojik yöntemlerin (örneğin transgenik bitkiler) tarımsal üretimde kullanılması sizce doğru mu?' sorusuna 'fikrim yok' diyenlerin oranı \%32.0, 'Modern Biyoteknolojik yöntemlerin tıp alanında (örneğin şeker hastaları için insülün üretiminde) kullanılması sizce doğru mu?' sorusuna 'evet' diyenlerin oranı \%64.7 olarak tespit edilmiştir. 'GD bitki ya da gıdaların ülkemizde üretim ve satışına izin verilmeli mi?' sorusuna 'hayır' diyenlerin oranı \%64.3 olduğu halde, 'GD bitki ve GD gıdaların günümüzde marketlerde satıldığını düşünüyor musunuz?' sorusuna 'evet' diyenlerin oranı \%85.3 olarak belirlenmiştir. 'GD bitki ya da gıdaların etiketlenmesi tüketici olarak sizi rahatlatır mı sorusuna 'evet' diyenlerin oranı \%66.8 olurken 
'GD bitkiler sayesinde birim alandan daha fazla ürün alınabileceğini düşünüyor musunuz?' sorusuna 'evet' diyenlerin oranı \%63.4 olarak tespit edilmiştir. 'Ülkemizde gıda amaçlı olmayan Transgenik bitki yetiştiriciliğine sizce izin verilmeli mi?' sorusuna katılımcıların \%48.3'si hayır olarak cevap vermişlerdir. 'Ithal tarımsal ürünlerde GDO olduğunu düşünüyor musunuz?' sorusuna ankete katılan kişilerin \%72.0 'evet' olarak yanıtlamıştır. 'Sizce tarımsal üretimi artırmanın alternatif yolları aşağıdakilerden hangisi olabilir?' sorusuna 'ekim alanlarını artırmak' diyenlerin oranı \%52.9, 'daha fazla gübre ve ilaç kullanmak' diyenlerin oranı \%3.4, 'biyoteknolojik yöntemleri kullanmak' diyenlerin oranı \%35.6, 'ithalat yapmak' diyenlerin oranı \%0.6, 'hiçbir fikrim yok' diyenlerin oranı ise \%7.5 olarak tespit edilmiştir. 'Genetiği Değiştirilmiş Organizmalar (GDO), Genetiği Değiştirilmiş (GD) Bitkiler, Transgenik Bitkiler ya da GD Gıdalar hakkında yeterli bilgiye sahip olduğunuzu düşünüyor musunuz?' sorusuna 'hayır' diyenlerin oranı ise $\% 55.4$ olarak tespit edilmiştir. 'Balık geni aktarılmış domates yerine Arı geni aktarılmış domatesi tercih eder misiniz?' sorusuna 'hayır' diyenlerin oranı ise \%35.2olarak belirlenmiştir.

\section{Sonuç}

Ankete katılan öğrencilerin \%64.3'ügenetiği değiştirilmiş (GD) bitki ya da gıdaların ülkemizde üretim ve satışına izin verilmemesi gerektiğini savunurken, \%85.3 ise GD bitki ve GD gıdaların günümüzde marketlerde satıldığını düşünmektedirler. Çalışmaya katılan öğrencilerin $\% 66.8$ 'i GD bitki ya da gıdaların etiketlenmesinin tüketiciyi rahatlatacağını fakat bu işlemin tek başına yeterli olmayacağını düşünmektedir. Öğrencilerin \%72.1'iüzerinde GDO'lu olduğunun belirtilmesi durumunda dahi GD bitki ya da gıdaları satın almayacaklarını belirtmişlerdir. Katılımcıların \%73.1'i (Hayır + Fikrim yok) Genetiği Değiştirilmiş Organizmalar (GDO), Genetiği Değiştirilmiş (GD) Bitkiler, Transgenik Bitkiler ya da GD Gıdalar hakkında yeterli bilgiye sahip olmadıklarını beyan etmişlerdir.

Eletronik ve tıp gibi diğer bilim dallarına ait teknolojik yöntemleri kolayca kabul edip günlük hayatlarına kolayca adapte edebilen eğitimli genç nüfusun biyoteknolojik yöntemlerle geliştirilen GDO'lara karşı yetersiz bilgiye sahip olması ve özellikle bu teknolojilerin geliştirildiği

Çizelge 1. 2014 yılı itibari ile transgenik bitki ekimi yapan ülkeler, ekim alanları (milyon hektar) ve ekimi yapılan ürünler

Table 1. Global planting area of biotech crops in 2014: by Country (Million Hectares)

\begin{tabular}{llll} 
& Ulke & Alan (Milyon Hektar) & GDO' lu Urünler \\
\hline 1 & U.S.A & 73.1 & Mısır, Soya, Pamuk, Kanola, Şeker pancarı, Yonca, \\
2 & Brezilya & 42.2 & Soya, Mısır, Pamuk \\
3 & Arjantin & 24.3 & Soya, Mısır, Pamuk \\
4 & Hindistan & 11.6 & Pamuk \\
5 & Kanada & 11.6 & Kanola, Mısır, Soya, Şeker pancarı \\
6 & Çin & 3.9 & Pamuk, Papaya, Kavak, Domates, Tatı biber \\
7 & Paraguay & 3.9 & Soya, Mısır, Pamuk \\
8 & Güney Afrika & 2.7 & Mısır, Soya, Pamuk \\
9 & Pakistan & 2.8 & Pamuk \\
10 & Uruguay & 1.6 & Soya, Mısır \\
11 & Bolivya & 1.0 & Soya \\
12 & Filipinler & 0.8 & Mısır \\
13 & Avustralya & 0.5 & Pamuk, Kanola \\
14 & Burkina Faso & 0.5 & Pamuk \\
15 & Myanmar & 0.3 & Pamuk \\
16 & Meksika & 0.2 & Pamuk,Soya \\
17 & İspanya & 0.1 & Mısır \\
18 & Kolombiya & 0.1 & Pamuk, Mısır \\
19 & Sudan & 0.1 & Pamuk \\
20 & Honduras & $<0.5$ & Mısır \\
21 & Şili & $<0.5$ & Mısır, Soya, Kanola \\
22 & Portekiz & $<0.5$ & Mısır \\
23 & Küba & $<0.5$ & Mısır \\
24 & Çek Cumhuriyeti & $<0.5$ & Mısır \\
25 & Romanya & $<0.5$ & Mısır \\
26 & Slovakya & $<0.5$ & Mısır \\
27 & Kosta Rika & $<0.5$ & Pamuk, Soya \\
28 & Bangladeş & $<0.5$ & Patlıcan \\
& & \\
\hline & TOPLAM & &
\end{tabular}

Kaynak: (James 2014)

Source:(James 2014) 
ve uygulandığı fakültelere mensup öğrencilerin toplumun diğer kesimleri ile benzer şekilde düşünüyor olmaları oldukça dikkat çekicidir.

Anket sonuçları, 4 yıllık lisans eğitimleri süresince tarımsal uygulamalar hakkında çok detaylı dersler alan Ziraat Fakültesi öğrencilerinin biyoteknolojinin tarımdaki uygulamaları ve bunların ürünleri konularında yeterli bilgiye sahip olmadıkları, toplumun diğer kesimlerinde olduğu gibi konuyla ilgili kafa karışıklıklarının mevcut olduğunu, GDO ve modern biyoteknolojik yöntemler ile bunların ürünleri konularında çok önemli bilgi eksikliklerinin var olduğunu göstermektedir. Ziraat Fakültelerinin çok farklı

Çizelge 2. Çanakkale Onsekiz Mart Üniversitesi Ziraat fakültesinde öğrenim gören öğrencilere GDO ile ilgili sorulan sorular ve öğrencilerin bu sorulara verdikleri yanıtlar

Table 2. GMO Related Questions and Answers of the Students Having Education in Faculty of Agriculture, Canakkale Onsekiz Mart University

\begin{tabular}{|c|c|c|c|c|}
\hline Soru & Evet & Hayır & $\begin{array}{l}\text { Fikrim } \\
\text { Yok }\end{array}$ & Toplam \\
\hline $\begin{array}{l}\text { 1-GDO'ların insan sağlığı ve çevre açısından zararlı } \\
\text { olduğunu düşünüyor musunuz? }\end{array}$ & 85.9 & 9.9 & 4.2 & 100 \\
\hline $\begin{array}{l}\text { 2-Sizce günümüzde kanser ve şeker hastalıklarının bu } \\
\text { kadar yaygınlaşmasında GDO'larındoğrudan bir katkısı var } \\
\text { mıdır? }\end{array}$ & 63.5 & 15.3 & 21.2 & 100 \\
\hline 3-Sizce GD bitki ya da gıdalar güvenli midir? & 13.5 & 72.0 & 14.5 & 100 \\
\hline $\begin{array}{l}\text { 4-GD bitki ya da gıdaların üzerinde GDO'luolduğunun } \\
\text { belirtilmesi durumunda satın alır mısınız? }\end{array}$ & 18.8 & 72.1 & 9.1 & 100 \\
\hline $\begin{array}{l}\text { 5-GDO kullanımının sigara ya da cep telefonu kullanımına } \\
\text { göre insan sağlığına daha zararlı olduğunudüşünüyor } \\
\text { musunuz? }\end{array}$ & 41.3 & 33.9 & 24.8 & 100 \\
\hline $\begin{array}{l}\text { 6-GD bitki ve gıdaların, yanlış zaman ve ölçüde kullanılan } \\
\text { tarım ilaçlarından daha tehlikeli olduğunu düşünüyor } \\
\text { musunuz? }\end{array}$ & 45.9 & 32.8 & 21.3 & 100 \\
\hline $\begin{array}{l}\text { 7-Modern Biyoteknolojik yöntemlerin (örneğin transgenik } \\
\text { bitkiler) tarımsal üretimde kullanılması sizce doğru mudur? }\end{array}$ & 39.3 & 28.6 & 32.0 & 100 \\
\hline $\begin{array}{l}\text { 8-Modern Biyoteknolojik yöntemlerin tıp alanında (örneğin } \\
\text { şeker hastaları için insülün üretiminde) kullanılması sizce } \\
\text { doğru mudur? }\end{array}$ & 64.7 & 15.5 & 19.7 & 100 \\
\hline $\begin{array}{l}\text { 9-GD bitki ya da gıdaların ülkemizde üretim ve satışına izin } \\
\text { verilmeli midir? }\end{array}$ & 22.9 & 64.3 & 12.8 & 100 \\
\hline $\begin{array}{l}\text { 10-GD bitki ve GD gıdaların günümüzde marketlerde } \\
\text { satıldığını düşünüyor musunuz? }\end{array}$ & 85.3 & 7.6 & 7.1 & 100 \\
\hline $\begin{array}{l}\text { 11-GD bitki ya da gıdaların etiketlenmesi tüketici olarak sizi } \\
\text { rahatlatır mı? }\end{array}$ & 66.8 & 25.3 & 7.9 & 100 \\
\hline $\begin{array}{l}\text { 12-GD bitkiler sayesinde birim alandan daha fazla ürün } \\
\text { alınabileceğini düşünüyor musunuz? }\end{array}$ & 63.4 & 19.1 & 17.5 & 100 \\
\hline $\begin{array}{l}\text { 13-Ülkemizde gıda amaçlı olmayan Transgenik bitki } \\
\text { yetiştiriciliğine sizce izin verilmeli midir? }\end{array}$ & 26.9 & 48.3 & 24.8 & 100 \\
\hline $\begin{array}{l}\text { 14-İthal tarımsal ürünlerde GDO olduğunu düşünüyor } \\
\text { musunuz? }\end{array}$ & 72.0 & 12.7 & 15.3 & 100 \\
\hline $\begin{array}{l}\text { 15-Genetiği Değiştirilmiş Organizmalar (GDO), Genetiği } \\
\text { Değiştirilmiş (GD) Bitkiler, Transgenik Bitkiler ya da GD } \\
\text { Gıdalar hakkında yeterli bilgiyesahip olduğunuzu } \\
\text { düşünüyor musunuz? }\end{array}$ & 26.9 & 55.4 & 17.7 & 100 \\
\hline $\begin{array}{l}\text { 16-Balık geni aktarılmış domates yerine Arı geni aktarılmış } \\
\text { domatesi tercih eder misiniz? }\end{array}$ & 24.1 & 35.2 & 40.7 & 100 \\
\hline $\begin{array}{lrll}\text { 17-Sizce } & \text { tarımsal } & \text { Ekim alanlarını } & \text { Biyoteknolojik } \\
\text { üretimi artırmanın } & \text { artırmak } & \text { yöntemler } \\
\text { alternatifyolları } & & \text { kullanmak } \\
\text { aşağıdakilerden } & & \end{array}$ & $\begin{array}{l}\text { Daha fazla } \\
\text { gübre ve } \\
\text { ilaç } \\
\text { kullanmak }\end{array}$ & $\begin{array}{l}\text { İthalat } \\
\text { yapmak }\end{array}$ & $\begin{array}{l}\text { Hiçbir } \\
\text { fikrim } \\
\text { yok }\end{array}$ & Toplam \\
\hline hangisi olabilir? $\quad 52.9$ & 3.4 & 0.6 & 7.5 & 100 \\
\hline
\end{tabular}


bölümlerinde öğrenim gören öğrencilerin popüler ve kamuoyuna mal olmuş olan tarımsal uygulamalar hakkında kendilerini yetiştirmeleri gerektiği, bölümlerde buna yönelik derslerin okutulmasının yerinde olacağı düşünülmektedir.

\section{Teşekkür}

SPSS programı ve örnekleme yönteminin belirlenmesindeki katkılarından dolayı Ögr. Gör. Yeşim MERAL'e teşekkür ederiz.

\section{Kaynaklar}

Collins M., 1986. Sampling, Consumer Market Research Handbookcountry-of-originlabeling, Journal of Agricultureand Applied Economics, 37.1(April 2005):49-63pp.

Duvick D.N., 2001. Biotechnology in the 1930s: the development of hybridmaize. NatRevGenet2:69-74.

James C., 2014. Preview: Global Status of Commercialized Biotech/GM Crops: 2014 ISAAA, Ithaca, NY. 